\title{
Da incondicionalidade: universidade, ciências, filosofia
}

\author{
On inconditionality: university, sciences, philosophy
}

\author{
Fernando Fragozo \\ Professor Associado \\ Programa de Pós-Graduação \\ em Filosofia da UFRJ \\ e-mail: ferfra3@gmail.com
}

Recebido em 06/05/2018

Aceito em 15/05/2018

\section{RESUMO}

O presente artigo tem como objetivo relacionar duas conferências tardias realizadas por Jacques Derrida a respeito da universidade e das ciências. Num primeiro momento, tratar-se-á de apresentar as linhas gerais de $A$ universidade sem condição, de 1998, na qual o autor propõe pensar a "profissão de professor" a partir das questões da busca da verdade e da performatividade sob a égide do conceito de "universidade sem condição" ou "incondicional", visando a constituição paradoxal de "novas Humanidades" que, no seio da universidade, possam tanto pensar seus limites como a paradoxal questão do acontecimento. Em seguida, serão apresentados elementos da conferência $O$ "mundo" das luzes por vir (exceção, cálculo, soberania), de 2002, na qual o autor busca pensar a razão para além do que é caracterizado como projeto arquitetônico, sistemático e teleológico da filosofia, que ameaçaria, assim como toda teleologia, as racionalidades plurais das mais diversas ciências na medida em que condiciona e impede o advento "impossível" do "acontecimento".

Palavras-chave: universidade, ciências, incondicionalidade, teleologia, acontecimento

\section{ABSTRACT}

This article aims to relate two conferences held by Jacques Derrida about the university and the sciences. At first, it will be presented the general lines of The future of the profession..., a conference presented in 1998, in which the author thinks the "profession of the professor" in relation with the search for truth and performativity under the concept of "university without condition", aiming at the paradoxical constitution of the "new Humanities" which, within the university, can both think its limits and the question of the event. Elements of the conference The "world" of the Enlightment to come (exception, calculation, sovereignty), 2002, will then be presented, in which the author seeks to think reason beyond what is characterized as an architectural, systematic and teleological project of philosophy, which would, like all teleology, threaten the pluralistic rationalities of the most diverse sciences insofar as it conditions and prevents the "impossible" advent of the "event."

Keywords: university, sciences, inconditionality, teleology, event 


\section{A universidade incondicional}

Em 1998, Jacques Derrida apresentou, em Stanford, na Califórnia, a conferência intitulada The future of the profession or the university without condition (thanks to the "Humanities", what could take place tomorrow)1. Nessa conferência, Derrida realiza o que ele propõe ser uma "profissão de fé: fé na Universidade e, nela, fé nas Humanidades de amanhâ", e especifica que "o longo título proposto significa primeiramente que a universidade moderna deveria ser sem condição" (DERRIDA, 2001, p. 11), o que significa, para Derrida, a incondicional possibilidade de tudo questionar, e isso, privilegiadamente, nas e pelas "novas Humanidades".

Desenvolve Derrida no início da conferência uma longa argumentação rememorativa das "promessas" da universidade moderna, notadamente de seu "compromisso sem limites para com a verdade" (Ibid., p. 12), por mais que "verdade" seja conceito a ser infinitamente discutido, justamente no seio da universidade. Lembra também do compromisso da universidade com a "luz", o Esclarecimento ou o Iluminismo, e a associação radical entre a busca de verdade e de luz com a questão do homem, entendida essa sob a égide de um "conceito do próprio do homem" que "fundou tanto o Humanismo como a ideia histórica das Humanidades" (Ibid., p. 12) e cuja rede conceitual ("próprio do homem", "direitos do homem", "crime contra a humanidade") governa hoje o processo da "mundialização" sob a pretensão de uma "humanização" (Ibid., p. 13).

Constata Derrida que, se esses conceitos são ao mesmo tempo indispensáveis e problemáticos, sua discussão ou reelaboração deve ser realizada, enquanto tal, de modo incondicional e sem pressupostos, no "espaço das novas Humanidades" - tal será sua "tese sob a forma de uma profissão de fé". E Derrida acrescenta: "Não para aí se fechar, mas pelo contrário, para encontrar o melhor acesso a um novo espaço público transformado pelas novas técnicas de comunicação, de informação, de arquivamento e de produção de saber" (Ibid., p. 13).

E, se essa universidade sem condições não existe de fato, ela deveria, em princípio, devido à sua "vocação declarada", ser "um último lugar de resistência crítica", "mais que crítica" - o que significa "desconstrutiva":

Clamo pelo direito à desconstrução como direito incondicional de levantar questões críticas não apenas à história do conceito de homem mas à própria história da noção de crítica, à forma e à autoridade da questão, à forma interrogativa do pensamento (Ibid., p. 14).

Trata-se de um "princípio de resistência incondicional" que a universidade deveria simultaneamente "refletir, inventar e estabelecer" (Ibid. p. 15), e isso de modo afirmativo e performativo, produzindo "eventos" e "obras" singulares.

Incondicionalidade e performatividade são assim os dois eixos centrais que guiarão Derrida ao longo da conferência. Dois eixos centrais da universidade e do que o autor denomina, aqui, de "novas Humanidades". É em torno desses eixos, e a partir de seu entrelaçamento, que a questão do "professar" (da "profissão" como métier ou da "profissão" como declaração (de fé)), será desdobrado, e que justifica o ambíguo título inglês da conferência: o futuro da profissão².

1 Publicada posteriormente, pelo próprio autor, também em francês, sob o título L'Université sans condition (DERRIDA 2001 e 2002). A tradução para o português foi publicada em 2003 sob o título A Universidade sem condição. Nesse artigo, será utilizada a versão francesa, e todas as traduções são de minha responsabilidade.

2 É impossível deixar de aproximar a presente conferência da quase centenária (em 1998) conferência de Max Weber sobre a Ciência como Vocação. A desilusão e a fria (por mais que, por vezes, irônica) constatação das condições da universidade, notadamente a alemã, no início do século XX, por Weber, contrastam de modo notável com a posição (apesar de tudo o que depõe contra a incondicionalidade na (atual) universidade) esperançosa e "messiânica" de Jacques Derrida. Note-se também que os termos utilizados para "profissão", em alemão e em francês (no caso, semelhante ao português), conotam diferentes movimento da voz: Beruf corresponde a algo da ordem de um "chamado", um "chamamento", enquanto profession aponta para uma "declaração". Muito haveria que comentar sobre essa diferença, e sobre as duas conferências em questão, notadamente diante da posição que Derrida apresentará em última instância na conferência, a saber, a "experiência do acontecimento", que diz certamente respeito a uma aceitação, a uma hospitalidade, diante do que advém - mas tal análise foge ao escopo do presente trabalho. 
Uma universidade sem condição é aquela na qual subsiste o "direito de tudo dizer" e de "dizê-lo publicamente". Força invencível da universidade, esse princípio de jure, não existe de facto. "Invencibilidade abstrata e hiperbólica", essa incondicionalidade impossível expõe justamente o outro sentido do termo "sem condição": sua "fraqueza" ou "vulnerabilidade" diante de todos "os poderes que a comandam, a cercam e tentam dela se apropriar" (Ibid., p. 18) - poderes estatais, econômicos, midiáticos, políticos, militares, religiosos... E se Derrida se utiliza do termo "sem condição" no lugar, e como sinônimo, de "incondicional" é porque quer justamente enfatizar a conotação do "sem poder" e "sem defesa" que caracteriza a universidade assim pensada. Ressalta Derrida que, quando pensa "universidade", o está fazendo distinguindo o conceito de todo e qualquer "centro de pesquisa" que esteja a "serviço de finalidades e de interesses econômicos de todo tipo" (Ibid., idem).

Aqui situa-se o ponto central da discussão que, a meu ver, liga de modo radical a presente conferência à conferência de 2002. Quando Derrida pensa a questão da incondicionalidade, ele o faz em contraposição à questão da soberania, tal qual ela sempre foi entendida como local de supremo poder. Se a "universidade incondicional" é aquela que afirma uma "independência incondicional", ela, na verdade, reivindica "uma espécie excepcional de soberania” (Ibid., p. 19, grifo meu); excepcional porque justamente sem condição no segundo sentido do termo: sem poder. Posição paradoxal na medida em que a soberania se caracteriza justamente pelo seu poder. Mas ainda mais paradoxal na medida em que o objetivo de Derrida é justamente pensar esse "futuro da profissão", mote central da conferência, relacionando essa universidade incondicional, excepcionalmente soberana, com a questão da performatividade, por mais que a performatividade ainda se encontre "do lado dessa soberania que eu gostaria, tão difícil que isso possa parecer, de distinguir de uma certa incondicionalidade em geral, de uma incondicionalidade sem poder" (Ibid., p. 15).

Um primeiro problema assim se apresenta na medida em que a performatividade diz respeito a algum tipo de posicionamento, a uma posição, e portanto a algum tipo de soberania. Como Derrida lidará com essa tensão? Entendendo que a profissão de professor diz respeito a uma performatividade que não é da ordem do posicionamento, mas de uma "afirmação" que não se reduza à "positividade de uma posição" (Ibid., idem). Isso significará, para Derrida, pensar a profissão de professor intrinsecamente como uma aporia:

1. Trata-se de um "trabalho", um métier (uma competência, um saber, um savoir-faire) diretamente relacionado com a produção e o ensino de um "conteúdo" de ordem teórica ou constatativo. Certamente, esse métier pode ser pensado como uma "performance", mas uma tal performance propõe-se ater ao ato de produzir ou ensinar "teoria": "o ato de professar uma doutrina pode ser um ato performativo, mas a doutrina não o é" (Ibid., p. 42). Trata-se, para Derrida, de uma "limitação" que é preciso conservar "pois um certo teoretismo neutro é a chance da incondicionalidade crítica e mais que crítica (desconstrutiva) (...) da qual, em princípio, não abrimos mão na universidade" (Idem). Neste sentido, a performatividade da profissão de professor não seria da ordem de um posicionamento, mas o de uma busca de constatação e de transmissão dessa constatação - em outras palavras, de busca de "teoria", "teoricamente" "neutra".

2. Ora, para Derrida, essa performatividade pretensamente "neutra", que é preciso conservar no ato de professar uma doutrina deve também ser alterada (Ibid., p. 42). Deve ser alterada porque é preciso justamente afirmá-la, em outras palavras, é preciso posicionar-se (ato performativo) em favor do "teoretismo incondicional". Professar esse "teoretismo incondicional" supõe sempre "uma profissão de fé performativa, uma crença, uma decisão, um engajamento público, uma responsabilidade ético-política” (Ibid., p. 43). Em outras palavras, a profissão de professor (que seria eminentemente constatativa, "teorética") demanda uma profissão de fé (e portanto uma performatividade) da ordem de um engajamento na "teoria", poderíamos dizer, na "verdade" e na "luz".

Isso quer dizer, assinala Derrida, que não há espaço, assim entendida a ambiguidade da profissão de professor, na universidade, "nem para um trabalho não teórico, nem para discursos de tipo performativo, nem, a fortiori, para esses atos performativos singulares engendrando hoje, em alguns locais das Humanidades de hoje, o que chamamos de obras" (Ibid., p. 43).

Um segundo problema aqui se coloca, pois o que Derrida pretende problematizar, e mesmo defender, é justamente a realização, na universidade, e mais especificamente no seio das "novas Humanidades", de "obras". 
Por mais que insista e reforce a ideia segundo a qual "esse espaço de tipo acadêmico deve ser simbolicamente protegido por uma espécie de imunidade absoluta" (mesmo se "a proteção dessa imunidade acadêmica não é jamais pura" e se "ela pode desenvolver perigosos processos de autoimunidade") (Ibid., p. 45), Derrida se pergunta se algo aconteceu, está em vias de acontecer ou está votado a acontecer a essa universidade clássico-moderna e às Humanidades; e, se tal é o caso, se isso alteraria a sua essência ou revelaria uma radical discrepância entre sua definição e sua efetivação. Resumindo em uma só questão o que aqui apresentamos como dois problemas referentes à questão da incondicionalidade e da performatividade na universidade (e, mais particularmente, nas Humanidades) diante do que pode estar em vias de acontecer, hoje, Derrida se pergunta: "O que acontece a partir do momento em que levamos em consideração não apenas o valor performático da 'profissão' mas aceitamos que um professor produza 'obras' e não apenas conhecimentos ou pré-conhecimentos?” (Ibid., p. 47)3.

Tal pergunta se faz no horizonte do reconhecimento ("consenso do qual partirei") de que "algo de grave de fato acontece, está em vias de acontecer ou a ponto de acontecer ao que chamamos de 'trabalho', 'teletrabalho', 'trabalho virtual', tanto quanto ao que chamamos de 'mundo' - e assim ao ser-no-mundo do que ainda se chama homem" (Ibid., p. 55). Ciberespaço, internet, telefones celulares estão na origem dessa mutação, que atinge diretamente a virtualização do trabalho, a comunidade de saber, a própria comunitarização e toda comunidade, assim como a experiência do lugar, do acontecer (avoir lieu), da obra e do acontecimento. O que determina, para Derrida, a necessidade imediata de pensar e repensar, sob o modo histórico e conceitual, sociológico e semântico, a diferença entre trabalho, atividade, profissão em geral e profissão de professor, produção, tekhnè, artes liberais e mercenárias (tal como Kant as nomeia). O que o leva a apresentar sete proposições para as Humanidades que se centram fundamentalmente na tarefa de "conhecer e pensar a sua própria história" (Ibid., p. 64), mais especificamente (pp. 68-73):

1. a história do homem, da ideia de homem, da figura e do "próprio do homem";

2. a história da democracia e da ideia de soberania;

3. a história do "professar", da "profissão" e do professorado - história "que se articula à história das premissas (notadamente abraâmicas, bíblicas e principalmente cristãs) do trabalho e da confissão mundializada" (p. 70);

4. o conceito e a história da literatura - obra, assinatura, autor, língua, ficção, direito de tudo dizer (ou não dizer);

5. a história da profissão, da profissão de fé, da profissionalização, do professorado; ${ }^{4}$

6. a história do "como se" e da distinção dos atos performativos e constatativos;

7. e, por fim (sem dúvida o ponto mais difícil, que desafia os próprios limites do pensamento), a questão do "acontecimento", do que "advém", lembrando que, em francês, "acontecer" se diz fundamentalmente como "ter lugar", avoir lieu.

3 Não fica claro, para mim, o porquê da insistência de Derrida na problematização da questão da performatividade por meio de "obras" de parte de "professores" - e o fato de "hoje" ser assim. Não porque, na conferência, o que Derrida proponha seja justamente a realização destas no seio da universidade e das "novas Humanidades", mas porque sempre foi presente e característica da universidade "moderna" a realização de "obras" - sejam elas "teoréticas" ou "artísticas". O que são, afinal, as Críticas kantianas, Ser e Tempo ou Gramatologia senão "obras" realizadas no seio mesmo da universidade por "professores"? Sem falar evidentemente nas obras de artistas, músicos, dramaturgos, mas também cientistas, que também eram "professores" e cuja história da universidade é plena de exemplos. Sem dúvida, o que Derrida quer enfatizar é a questão da "busca da verdade" como mote desse espaço incondicional, "neutro", que deve ser defendido (e questionado...) a todo custo. Mas a questão é: a "verdade" é apenas buscada por meio de "obras" "teoréticas"? Qual o espaço de "verdade" de "obras" de arte, por exemplo? - essa é a questão que, me parece, não justificaria pensar a performatividade universitária apenas como "profissão de fé" e a defesa da realização de "obras" na universidade não necessitaria, a rigor, ser feita.

4 Por que Derrida propõe um item que repete um outro anteriormente proposto (o de numero 3). Por mais que especifique, nesse item 5, que se trata do professor propriamente dito (e não apresente aspas como no item 3), e do questionamento de sua performatividade, é evidente a umbilical ligação com a questão proposta no item $3 \mathrm{em}$ torno do trabalho e da confissão (Beruf, tripallium, profiteor, etc.). 
Esse último ponto encerra a conferência abrindo a questão radical do acontecimento e da própria possibilidade de pensá-lo. É possível, pergunta-se Derrida, perguntar-se "o que é" um "acontecimento"? Se um acontecimento é certamente uma suspensão de uma constatação corrente, não é menos verdade que não corresponde exatamente à irrupção de um ato performativo que venha justamente realizar essa suspensão. Não que "nada aconteça" com um ato performativo mas, diz Derrida, o que acontece, o que "me acontece", no âmbito de uma performance "ainda permanece controlável e programável em um horizonte de antecipação ou de précompreensão: em um horizonte tout court". E acrescenta: "É da ordem do possível controlável, é o desdobramento do que já é possível. É da ordem do poder, do 'eu posso"' (Ibid., p. 73). Ora, um "acontecimento" digno desse nome, para Derrida, corresponde a uma irrupção radical que rebenta o horizonte, "interrompendo toda organização performativa, toda convenção" e, nesse sentido, "apenas o impossível pode acontecer/vir/chegar (arriver)" (p. 74). Esse pensamento do acontecimento como o impossível que vem é certamente tema central da reflexão de Derrida e, na conferência, chama ele a atenção para o fato de já vir tentando pensá-lo por meio de "exemplos" - na verdade, os conceitos, ou quase-conceitos, de invenção, dom, perdão, hospitalidade, justiça e amizade, dentre outros.

Trata-se de pensar o que pode ser de modo radical - impossível até. "Pode ser" em francês se diz peu$t$-être, que corresponde também a "talvez". Aproxima então Derrida esse "pode ser/talvez" do condicional hipotético "se", "de uma certa gramática do condicional: 'e se isso acontecesse? Isso, que é totalmente outro, bem poderia acontecer" (Ibid., p. 76). Ora, complementa o autor, esse "pode ser" que ele quer pensar não é propriamente da ordem do condicional, ele rompe justamente com o que poderíamos chamar de "possibilidade condicionada" , que ainda estaria na ordem dos possíveis pensáveis. O que Derrida quer pensar é justamente "o possível acontecimento do incondicional impossível, o inteiramente outro" (Ibid., idem) - e não se trata aqui de uma posição teológica.

Essa seria "no fundo, peut-être" sua "hipótese", "extremamente difícil e quase im-provável, inacessível a uma prova": "uma certa independência incondicional do pensamento, da desconstrução, da justiça, das Humanidades, da Universidade, etc., deveria ser dissociada de todo fantasma de soberania indivisível e de controle (maîtrise) soberano" (Ibid., idem). As "Humanidades" seriam o local privilegiado para pensar os limites dessa "autoridade performativa" que, de algum modo, apresenta delimitações e se enquadra em projeções possíveis. Ora, ao entabular esse pensamento - e é isso que interessa a Derrida -, se é transportado para um outro lugar, justamente para o limite entre o interior e o exterior da universidade e das próprias Humanidades. Ao pensar os limites da performatividade e a radical imprevisibilidade do que advém sem condição, coloca-se justamente em questão os limites da universidade: "pensa-se no âmbito das Humanidades que não se pode e não se deve enclausurar-se no interior das Humanidades” (Ibid., p. 77). Mas, para isso, são justamente necessárias as Humanidades.

Em outras palavras, o que Derrida está defendendo aqui é que não há limites fixos da universidade, se esta for entendida como local de incondicional questionamento, de radical interrogação, em busca de "verdade" e de questionamento da "verdade". Mas para pensar esse limite sempre fluido da universidade de modo "forte e consequente" (Ibid., idem), são justamente requeridas as Humanidades. Porque, para o autor, é nesse

limite sempre divisível que o que acontece, acontece. É esse limite que é afetado e que muda. É ele que, porque é divisível, tem uma história. Esse limite do impossível, do "pode ser/talvez (peut-être)" e do "se", tal é o lugar no qual a universidade divisível expõe-se à realidade, às forças do exterior (que elas sejam culturais, ideológicas, políticas, econômicas ou outras). É aí que a universidade está no mundo que ela tenta pensar. (Ibid., pp. 77, 78)

E pensar quer singularmente dizer "resistir". Resistir, com suas obras, às "tentativas de reapropriação (política, jurídica, econômica, etc.)", mas não para se encerrar em uma pretensa "soberania" abstratamente

$5 \quad$ O termo não é de Derrida. 
fantasmática mas para se unir, nessa resistência, justamente às forças extra-acadêmicas - o que, em última instância, quer dizer propor uma outra "topologia":

a universidade sem condição não se situa necessariamente, nem exclusivamente, no recinto do que chamamos hoje de universidade. Ela não é necessariamente, exclusivamente, exemplarmente representada na figura do professor. Ela acontece [tem lugar, a lieu], ela busca seu lugar em todo lugar onde essa incondicionalidade pode se anunciar. (Ibid., p. 78)

Uma universidade, "novas Humanidades", que possam pensar e se pensar no além de si mesmas na medida em que o que está em jogo é a possibilidade de permanente questionamento incondicional que coloque também em questão esse próprio lugar do pensamento. Tensão ou aporia infindável, pois é na universidade e, mais particularmente como proposto nessa conferência, nas "Humanidades", que Derrida vê o local possível para se pensar o além comum dessas forças de resistência. A universidade é, assim, simultaneamente, local privilegiado e local questionado no questionamento incondicional; é simultaneamente uma instituição efetiva, situada, delimitada em seus órgãos, conselhos, unidades, mas que questiona justamente essa estrutura e essa delimitação, seus limites e seu além, identificando "forças" que, nesse "extra-muros", também se situam na mesma "posição". E isso, num horizonte que hoje desloca de modo inaudito, e constante, as fronteiras conceituais, topológicas, institucionais...

Há certamente um privilégio da universidade, e particularmente das "Humanidades", nessa conferência. Mas esse privilégio é justamente identificado na medida em que são esses "locais" que poderiam radicalmente pensar a questão do privilégio e da soberania. Ora, essa posição que vê nas "novas Humanidades" esse paradoxal privilégio será desdobrado de forma ampliada a fim de pensar a soberania e a incondicionalidade enquanto tais, a partir de uma radical reflexão sobre a razão, em outra conferência pronunciada em 2002. Ali, a contraposição se dá fundamentalmente entre a pretensão arquitetônica, sistemática e unificadora da filosofia e a pluralidade das ciências.

\section{As ciências incondicionais}

"Numa certa medida pelo menos, a filosofia é para a desconstrução simultaneamente uma referência, um recurso $e$ um alvo privilegiado" (DERRIDA, 2001a, p. 64). É assim que Derrida descreve em poucas palavras a relação da desconstrução com a filosofia na conferência de 1998 que acabamos de analisar. Certamente, uma tal postura é constante em toda a sua obra, caracterizada justamente pela andança pelas "margens da filosofia". Ora, no caso da universidade, Derrida propõe, a partir das análises de Le Goff, que esta "se pensa e se representa desde o local privilegiado do filosófico" e assim o faz "dentro e fora das Humanidades" desde a Idade Média e até Kant, pelo menos (Ibid., idem). Na conferência de 1998, Derrida não aponta especificamente para a presença explícita, na "arquitetura da universidade" contemporânea, para o privilégio da filosofia. É certamente de se questionar se, hoje, tal é o caso, de modo explícito e estrutural. No entanto, o que Derrida constata, agora não mais na conferência de 1998, mas na que pronunciou em 2002, em Nice, no Congresso da Associação das Sociedades de Filosofia de Língua Francesa, e que tem como título $O$ "mundo" das Luzes por vir (exceção, cálculo, soberania), é a presença, poderíamos dizer, "espectral", do que denomina de "estruturação da racionalidade filosófica" no direcionamento - e na inibição - das pesquisas em todos os campos do saber.

Se o mote central da conferência de Nice é a "hipótese" segundo a qual seria necessário "salvar a honra da razão" (2003, p. 167), o que Derrida propõe realizar é propriamente uma reflexão sobre as características estruturais do pensamento filosófico na medida em que este é visto por Derrida como inibidor dos desdobramentos (im)possíveis das diversas ciências. Isso porque Derrida se pergunta se não é justamente essa visão da racionalidade que permeia a filosofia desde seus primórdios - e que é propriamente a filosofia - que ameaça a razão, a possibilidade da racionalidade. Em outras palavras, Derrida distingue a razão, em geral, da filosofia; para ele, o que ocorre no âmbito da filosofia é propriamente um projeto, certamente racional, de totalização sistemática e teleológica. Trata-se, a rigor, de uma tese sobre a razão, que encontra na formulação 
kantiana "a razão humana é, por natureza, arquitetônica" (ApudDERRIDA, 2003, p. 169), sua explícita formulação.

Ora, Kant defende claramente que a razão humana "só admite princípios que, pelo menos, não impeçam qualquer conhecimento dado de coexistir com outros num sistema" (KANT, 2001, p. 483; no original, A474 B502), formulação que se baseia, como lembra Derrida, na "Ideia reguladora da razão" da unidade do "mundo" cuja "unificação da experiência que o totaliza requer um 'como se' (als ob)" (DERRIDA, 2003, p. 171). Em outras palavras, o que Derrida quer assinalar é que a formulação kantiana da unidade do "mundo" é fundamentalmente uma hipótese, um pressuposto central e essencial para Kant, sem o qual, no próprio dizer de Kant, "não teríamos qualquer ordem da natureza segundo leis empíricas" (2012, p. 17).

Tal postura se refletiria também em Husserl, e é nesse sentido que Derrida centra sua análise nesses dois grandes idealismos transcendentais: ambos são paradigmáticos da posição da filosofia no sentido de visar a construção de um edifício sistemático a partir de um "desejo ou interesse arquitetônico" (DERRIDA, 2003, p. 170). ${ }^{6}$ O que Derrida vai assim se perguntar é se esse "desejo ou interesse", se essa hipótese ou postulação de um ordenamento arquitetônico não corre o risco de "violentar" as mais diversas ciências em sua "heterogeneidade intraduzível, sem analogia" (Ibid., p. 171). "Racionalidades plurais" que devem (trata-se, aqui, para Derrida, de necessidade) ser levadas em conta em suas "regiões ontológicas", necessidades específicas, estilo, axiomática, instituições, comunidades e historicidades próprias (Ibid., p. 170). E que resistem, "nas diferenças entre as matemáticas, as ciências da natureza ou da vida, as ciências humanas, as ciências sociais ou do espírito, a física tanto quanto a biologia, o direito ou a economia política, a ciência política, a psicologia, a psicanálise, a teoria literária" a um "ordenamento arquitetônico" (Ibid., idem).

A oposição que Derrida assim apresenta é eminentemente entre o que ele denomina de "razão arquitetônica", característica da filosofia, e as "racionalidades plurais", características das ciências. O problema é justamente que a filosofia, com seu projeto de sistematização arquitetônica, apresenta-se como um teleologismo - a rigor, como o grande teleologismo ocidental que põe em risco a pluralidade dos saberes. É nesse sentido que Derrida se pergunta:

Não é então em nome dessas racionalidades heterogêneas, de sua especificidade e de seu futuro, de sua história, de suas 'luzes', que é preciso por em questão a autoridade magistral e dominadora da arquitetônica e, assim, de um certo 'mundo', de uma unidade da Ideia reguladora de mundo que antecipadamente a autoriza? (Ibid., p. 171).

Na verdade, Derrida está preocupado com todo tipo de teleologismo, com todo tipo de questionamento, pensamento e/ou pesquisa científica, dirigido ou encaminhado por algum tipo de objetivo ou antecipação, condicionado ou controlado por "toda sorte de poder ou de instituição política, militar, tecno-econômica, capitalística” (Ibid., p. 199), e, mais profundamente, com a expectativa condicionante de uma totalização sistemática:

É a respeito dessa supremacia da ideia ou do telos, da razão ou do logos que a partir dele se ordena ou os ordena [a razão e o logos], é a respeito da ideo-logia e da teleo-logia, dessa razão da idealidade e dessa razão do telos que devemos levantar a questão do evento, do vir e do advir/futuro (avenir) do acontecimento (événement) (Ibid., p. 188).

A questão da incondicionalidade é aqui elaborada em função desse pano de fundo constitutivo do Ocidente em torno do vigor da filosofia, e esta é pensada a partir da indissociabilidade estrutural, que parece "para sempre irredutível", entre "a exigência de soberania em geral" e a "exigência incondicional do incondicionado" (Ibid., p. 195). O desafio para o autor é então "acordar o pensamento do acontecimento incondicional a uma razão outra que não (...) a razão clássica do que se apresenta ou anuncia sua apresentação 
segundo o eidos, o ideal, a Ideia reguladora ou, o que aqui corresponde ao mesmo, o telos" (Ibid., p. 189) - o que significa dissociar essas duas exigências, "distinguir, ali mesmo onde isso parece impossível, entre, de um lado, a compulsão ou a autoposição de soberania (...) e, de outro, essa postulação de incondicionalidade que se encontra tanto na exigência crítica quanto na exigência (...) desconstrutora da razão" (Ibid., p. 196).

Essa distinção corresponde ao que chamei, paradoxalmente, de "soberania incondicional do incondicionado" (FRAGOZO, 2012), como crítica/desconstrução permanente do que se constitui ou pode se constituir em soberania. Derrida reforça o fato de que se trata, para ele, nessa distinção de uma postulação, pois que é da ordem da demanda, do desejo ou da exigência imperativa e não do "princípio" ou do "axioma". Postulação que, evidentemente, em muito se aproxima da "profissão de fé" que propõe na conferência de Stanford.

Retoma então Derrida a discussão sobre o "acontecimento", aqui sob o pano de fundo do horizonte mais geral da razão ocidental, e apresenta uma caracterização geral do "acontecimento" em relação com a questão do teleologismo, e mais especificamente do teleologismo da filosofia, "idealismo teleológico" tal qual o nomeia:

Im-previsível, um acontecimento digno desse nome não deve apenas exceder todo idealismo teleológico, toda astúcia da razão teleológica que dissimularia o que poderia lhe acontecer e afetar sua ipseidade de modo auto-imunitário (...). O acontecimento deve se anunciar como im-possível, deve assim anunciar-se como sem prevenir, anunciarse sem anunciar-se, sem horizonte de espera, sem telos, sem formação, sem forma ou preformação teleológica. Daí seu caráter sempre monstruoso, inapresentável, e mostrável como imostrável (Ibid., p. 198).

E traz em seguida o questionamento para o que quer visar nessa conferência, a saber, as ciências, chamando a atenção para o fato de que, se "o acontecimento de uma invenção tecnocientífica" é possibilitado por um conjunto de condições que podem ser determinadas a posteriori pela epistemologia, a história ou a filosofia das tecnociências, não se trata mais de uma invenção ou um acontecimento. Porque, para o autor, "um acontecimento ou uma invenção apenas são possíveis como im-possíveis" (Ibid., idem).

Como reiteradamente proposto em seus escritos, trata-se não apenas do pensamento do impossível mas de um pensamento impossível. E, no entanto, necessário. Se, na conferência de Stanford, a ênfase na questão tecnológica era posta sobre o surgimento do ciberespaço, da internet e das tecnologias contemporâneas de comunicação, na conferência de Nice o foco é fixado na engenharia genética e notadamente na questão da "clonagem". O imperativo de pensar o impossível se dá assim não apenas como uma necessidade da razão em geral e enquanto tal (e lembremos, para Derrida a razão não se reduz à filosofia) mas como uma necessidade imposta pelo momento e pelas transformações tecnocientíficas que presenciamos e que não conseguimos antecipar - dizer o contrário seria assumir que já são conhecidas de antemão as possibilidades e impossibilidades geradas pelas tecnologias. Pensar o impossível é pensar que o que pode fugir completamente do horizonte no qual se está situado pode, como dito na conferência de 1998, "rebentar o horizonte". E não é por menos que Derrida propõe, explicitamente, que "o verdadeiro local de um problema da razão hoje" seja a técnica e, com ela (retomando o tema com outra dramaticidade dado que traz a clonagem para o diante da cena como a "metonímia" de "todas as urgências que nos assaltam"), a questão do "próprio do homem", do "próprio do corpo vivo" (2003, p. 200).

E, se a questão é pensar a desconstrução como

um racionalismo incondicional que não renuncia nunca, precisamente em nome das Luzes por vir, no espaço a abrir de uma democracia por vir, a suspender de modo argumentado, discutido, racional, todas as condições, as hipóteses, as convenções e as pressuposições, a criticar incondicionalmente todas as condicionalidades, inclusive aquelas que fundam ainda a idéia crítica, a saber, a do krinein, da krisis, da decisão e do juízo binário ou dialético (2003, p. 197), 
portanto como questionamento radical de toda "soberania", soberania essa que se encontra já sob questão na política (o que é, hoje, "estado-nação", "guerra" ou "terrorismo"?), no conceito de "homem" e de seus "direitos", não é menos importante, para Derrida, ser extremamente cauteloso com o questionamento, pensando cada contexto singular (e é evidente que a presença, que Derrida começou certamente a ver nos anos 2000, dos diversos nacionalismos, fascismos e movimentos de exclusão, intensificou-se dramaticamente nos últimos anos), notadamente diante de conceitos que é preciso simultaneamente manter e desconstruir, como "direitos do homem" e "estado-nação" (Ibid., p. 216) e decisões (im)possíveis que é preciso tomar mas pelas quais, dado o ineditismo, nenhum saber tem condições, de fato, de se responsabilizar.

\section{Referências bibliográficas}

DERRIDA, Jacques. A Universidade sem condição. Tradução de Evando Nascimento. São Paulo: Estação Liberdade, 2003.

Le "monde" des Lumières à venir (exception, calcul, souveraineté)". In: Voyous - Deux essais sur la raison. Paris: Galilée, 2003.

L’université sans condition, Paris: Galilée, 2001

The future of the profession or the university without condition (thanks to the "Humanities", what could take place tomorrow). In: COHEN, Tom (Ed.). Jacques Derrida and the humanities - A critical reader. Cambridge University Press, 2002.

FRAGOZO, Fernando. Razão e desconstrução: Derrida entre a soberania incondicional e a incondicionalidade soberana. Ensaios Filosóficos, Volume VI, pp. 71-82, Outubro/2012. Disponível em: http://www.ensaiosfilosoficos. com.br/. Acesso em: 03/05/2018 15:00.

KANT, Immanuel. Crítica da faculdade do juízo. Trad. de Valério Rohden e António Marques. 3. ed. Rio de Janeiro: Forense Universitária, 2012.

Crítica da razão pura. Trad. Manuela Pinto dos Santos e Alexandre Fradique Morujão. Lisboa: Fundação Calouste Gulbenkian, 2001. 